\title{
Influence of preparation conditions in the textural and chemical properties of activated carbons from a novel biomass precursor: The coffee endocarp Joa o Valente Nabais a,*, Peter Carrott a, M.M.L. Ribeiro Carrott a, Va^nia Luz a,
}

Angel L. Ortiz b

a Universidade de E' vora, Departamento de Quı́mica e Centro de Quı́mica de E' vora, Rua Romão Ramalho, 59, 7000 E' vora, Portugal

b Dep. de Ingenierı́a Meca' nica, Energe'tica y de los Materiales, Escuela de Ingenierı́as Industriales, Universidad de Extremadura,

Avda. de Elvas, s/n, 06071 Badajoz, Spain

Received 17 April 2007; received in revised form 18 December 2007; accepted 20 December 2007

Abstract

In this work a novel biomass precursor for the production of activated carbons (AC) was studied. The lignocellulosic material used as

precursor is the coffee bean endocarp, which constitutes an industrial residue from the Portuguese coffee industry. Activation by carbon

dioxide and potassium hydroxide produces activated carbons with small external areas and pore volumes up to 0.22 and $0.43 \mathrm{~cm}_{3} \mathrm{~g}_{-} 1$,

respectively, for $\mathrm{CO}_{2}$ and $\mathrm{KOH}$ activation. All the AC's produced are very basic in nature with point of zero charge higher than 8. SEM/

EDX studies indicate the presence of $\mathrm{K}, \mathrm{O}, \mathrm{Ca}$ and $\mathrm{Si}$. By FTIR it was possible to identify the formation on the AC's surface of several

functional groups, namely phenol, alcohol, quinone, lactone, pyrone and ether as well as SiAH groups. The tailoring of the porous and

chemical structure of the activated carbons produced is possible by selecting the appropriate production conditions.

_ 2008 Elsevier Ltd. All rights reserved. 